(c) 2021 Universidad Nacional Autónoma de México, Facultad de Estudios Superiores Zaragoza.

Este es un artículo Open Access bajo la licencia CC BY-NC-ND (http://creativecommons.org/licenses/by-nc-nd/4.0/).

TIP Revista Especializada en Ciencias Químico-Biológicas, 24: 1-16, 2021.

https://doi.org/10.22201/fesz.23958723e.2021.398

\title{
Nanoanticuerpos: desarrollo biotecnológico y aplicaciones
}

\author{
Paola Andrea Ortega-Portilla ${ }^{1 *}$, Laura Cancino-Villeda ${ }^{1,2}$, \\ Enrique Wenceslao Coronado-Aceves ${ }^{1}$ y Clara Espitia-Pinzón ${ }^{1}$ \\ ${ }^{1}$ Instituto de Investigaciones Biomédicas, Universidad Nacional Autónoma de México \\ (UNAM), Ciudad Universitaria, Circuito Escolar, Alcaldía Coyoacán, 04510 Ciudad \\ de México, México. ${ }^{2}$ Escuela Nacional de Ciencias Biológicas, Instituto Politécnico \\ Nacional. Ciudad de México, México.E-mail: *paoandortega3647@gmail.com
}

\section{RESUMEN}

Los anticuerpos monoclonales son una de las herramientas más revolucionarias en el área de la biomedicina por tener aplicaciones inmunoterapéuticas e inmunodiagnósticas. Sin embargo, el rápido avance tecnológico que demandan estas áreas genera la exploración de nuevas biomoléculas. El descubrimiento de anticuerpos compuestos únicamente por cadenas pesadas, presentes de forma natural en el suero de los camélidos y en algunas especies de tiburón, son motivo de estudio desde las últimas décadas como una alternativa a los anticuerpos convencionales. Estos poseen una región de reconocimiento antigénico, que consiste en un dominio variable por cada cadena, conocidos como anticuerpos de un solo dominio o nanoanticuerpos. Estas biomoléculas se caracterizan por tener un tamaño reducido, alta especificidad, estabilidad y bajo costo en su producción; propiedades que las convierten en una herramienta altamente versátil. En la presente revisión se abordarán aspectos relevantes de los nanoanticuerpos, como su descubrimiento, características estructurales, desarrollo en el campo de la biotecnología y su potencial de aplicación en enfermedades como el cáncer y en la identificación de microorganismos.

Palabras clave: nanoanticuerpos, Nanobodies, cáncer, inmunoterapia, industria farmacéutica.

\section{Nanobodies: Biotechnological development and applications}

\begin{abstract}
Monoclonal antibodies are one the most revolutionary tools in the biomedicine area for having immunotherapeutic and immunodiagnostic applications. However, the rapid technological advance demanded by these areas generates the exploration of new biomolecules. The discovery of antibodies composed solely of heavy chains, naturally present in the camelids' serum and some shark species, has been the subject of study since the last decades as an alternative to conventional antibodies. These have an antigen recognition region, which consists of a variable domain for each chain, known as single domain antibodies or nanobodies. These biomolecules are characterized by having a small size, high specificity, stability, and low cost in their production; properties that make them a highly versatile tool. This review will address relevant aspects of nanobodies, such as their discovery, structural characteristics, development in the field of biotechnology, and their potential for application in diseases such as cancer and in the identification of microorganisms.
\end{abstract}

Keywords: antibody, Nanobodies, cancer, immunotherapy, pharmaceutical industry. 


\section{INTRODUCCIÓN}

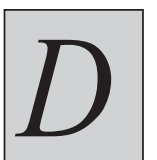

esde que Köhler y Milstein desarrollaron los anticuerpos monoclonales (Köhler \& Milstein, 1975), su aplicación ha sido ampliamente explorada en la identificación directa y/o indirecta de moléculas blanco, desarrollo biotecnológico, diagnóstico clínico e inmunoterapia, lo que manifiesta el impacto revolucionario de su descubrimiento para la humanidad. Sin embargo, a pesar de existir anticuerpos monoclonales aprobados para su uso en humanos (Singh et al., 2018), algunas características inherentes a su estructura como el tamaño, ha dificultado su aplicación terapéutica en áreas como el cáncer, debido a su baja diseminación en el tejido tumoral, el desarrollo de anticuerpos tipo HAMA (por el inglés Human Anti-Mouse Antibodies), baja estabilidad estructural en condiciones adversas y alto costo en su producción, han incentivado la búsqueda y desarrollo de nuevas alternativas.

El descubrimiento realizado por el grupo de Hamers-Casterman en 1993, en el que por serendipia encontraron anticuerpos compuestos únicamente por cadenas pesadas, presentes en el suero de Camelus dromedarius, seguido por la identificación de anticuerpos similares en el suero de Ginglymostoma cirratum más conocidos como tiburón nodriza (Greenberg et al., 1995), abrió la puerta a un panorama no explorado, puesto que la región de reconocimiento antigénica de estos anticuerpos, está formada por un dominio variable perteneciente a cada cadena pesada.

El porcentaje de este tipo de anticuerpos varía en función de las especies que los desarrollan de manera natural, en camellos se ha reportado que representan entre el 50 y el $80 \%$ y en tiburones de 0.1 a $1 \%$ del total de los anticuerpos. Las funciones que se les han atribuido son el reconocimiento de algunos virus y el reclutamiento celular (Muyldermans, 2013). Sus dominios variables son definidos como el formato de reconocimiento natural más pequeño que existe. Estos dominios comparten y difieren en algunas características estructurales en función de su origen, por esta razón, se han establecido nomenclaturas para su identificación. Los dominios variables de la cadena pesada de anticuerpos convencionales (humanos y de ratón tipo $\operatorname{IgG}$ ), son reconocidos como VH (del inglés Variable Heavy), por otro lado, a los derivados de anticuerpos de cadena pesada, presentes en tiburones, se les conoce como V-NAR (del inglés Variable New Antigen Receptor) y a los presentes en camélidos, como $\mathrm{V}_{\mathrm{H}} \mathrm{H}$ (del inglés Variable Heavy from Heavy Chain Antibodies) (Muyldermans, 2013). Estos últimos son más conocidos como Nanobodies (Nanoanticuerpos, $\mathrm{Nac}$ ), nombre adjudicado por Ablynx, una bio-farmacéutica de SANOFI dedicada al desarrollo de este formato de anticuerpo ablynx.com/our-company/ overview/ (Jovčevska \& Muyldermans, 2020).

Los Nac se caracterizan por su tamaño reducido, solubilidad, estabilidad y especificidad, lo que los convierte en una atractiva opción para su desarrollo y aplicación en diversas áreas, desde investigación básica hasta la evaluación de su potencial terapéutico. Esto representa una alternativa o complemento para los anticuerpos convencionales.

\section{NANOANTICUERPOS: ESTRUCTURA Y PROPIEDADES Estructura}

A diferencia de la estructura heterodimérica de la inmunoglobulina tipo $\operatorname{IgG}$ convencional, que consiste en 2 cadenas pesadas idénticas con 4 dominios y 2 cadenas ligeras idénticas con dos dominios y un peso de $\sim 150 \mathrm{kDa}$ (Padlan, 1994); los anticuerpos de cadena pesada tienen una estructura homodimérica en ausencia de cadenas ligeras, con dos dominios constantes $(\mathrm{CH} 2-\mathrm{CH} 3)$ en ausencia del dominio $\mathrm{CH} 1$ en camélidos y cinco dominios constantes en tiburones, con un peso de $\sim 90 \mathrm{kDa}$ (Muyldermans, 2013; Nuttal et al., 2001) (Figura 1).

Su región de reconocimiento antigénico, consiste únicamente en un dominio variable por cada cadena con un peso $\sim 15$ $\mathrm{kDa}$. Tienen cualidades estructurales únicas en función de su origen, por ejemplo, la presencia de 9 cadenas tipo Beta en camélidos y 7 en tiburones. Su capacidad de reconocimiento a pesar de tener un tamaño casi 10 veces menor a un anticuerpo convencional, ocurre gracias a la presencia de regiones determinantes de complementariedad, más conocidas como CDRs (del inglés Complementarity Determining Regions), donde también se han evidenciado diferencias, siendo 3 para camélidos y 2 para tiburones por cada dominio, pero en ambos casos CDR 1 y 3 tienen mayor longitud y variabilidad. El CDR3 de los nanoanticuerpos tiene 6 y 4 residuos de aminoácidos adicionales con respecto a los dominios de cadena pesada de los ratones y humanos respectivamente. Debido a estas condiciones, un puente disulfuro adicional entre CDR1 y CDR3 está presente y brinda estabilidad a la estructura. Esta interacción se encuentra ausente en los anticuerpos convencionales (Govaert et al., 2012; Stanfield, Dooley, Verdino, Flajnik \& Wilson, 2007).

Estas características les brindan una superficie suficiente para reconocer antígenos de forma similar a los fragmentos de reconocimiento de cadena sencilla compuestos por los dominios variables de cadena pesada y ligera (Siontorou et al., 2013).

En análisis de secuenciación, se ha identificado la sustitución de los residuos de aminoácidos hidrofóbicos conservados en los dominios variables de los anticuerpos convencionales, por residuos de aminoácidos de naturaleza hidrofílica. Estos cambios son adjudicados a la ausencia de la cadena variable ligera (Muyldermans, 2013), las sustituciones y posiciones de mayor importancia son: valina (42) por fenilalanina/tirosina, glicina (49) por ácido glutámico, leucina (50) por arginina y triptófano (52) por glicina (Muyldermans, 2013; Atarhouch, Saldanha, Barbosa \& Hamers, 1994; Harmsen et al., 2000). 


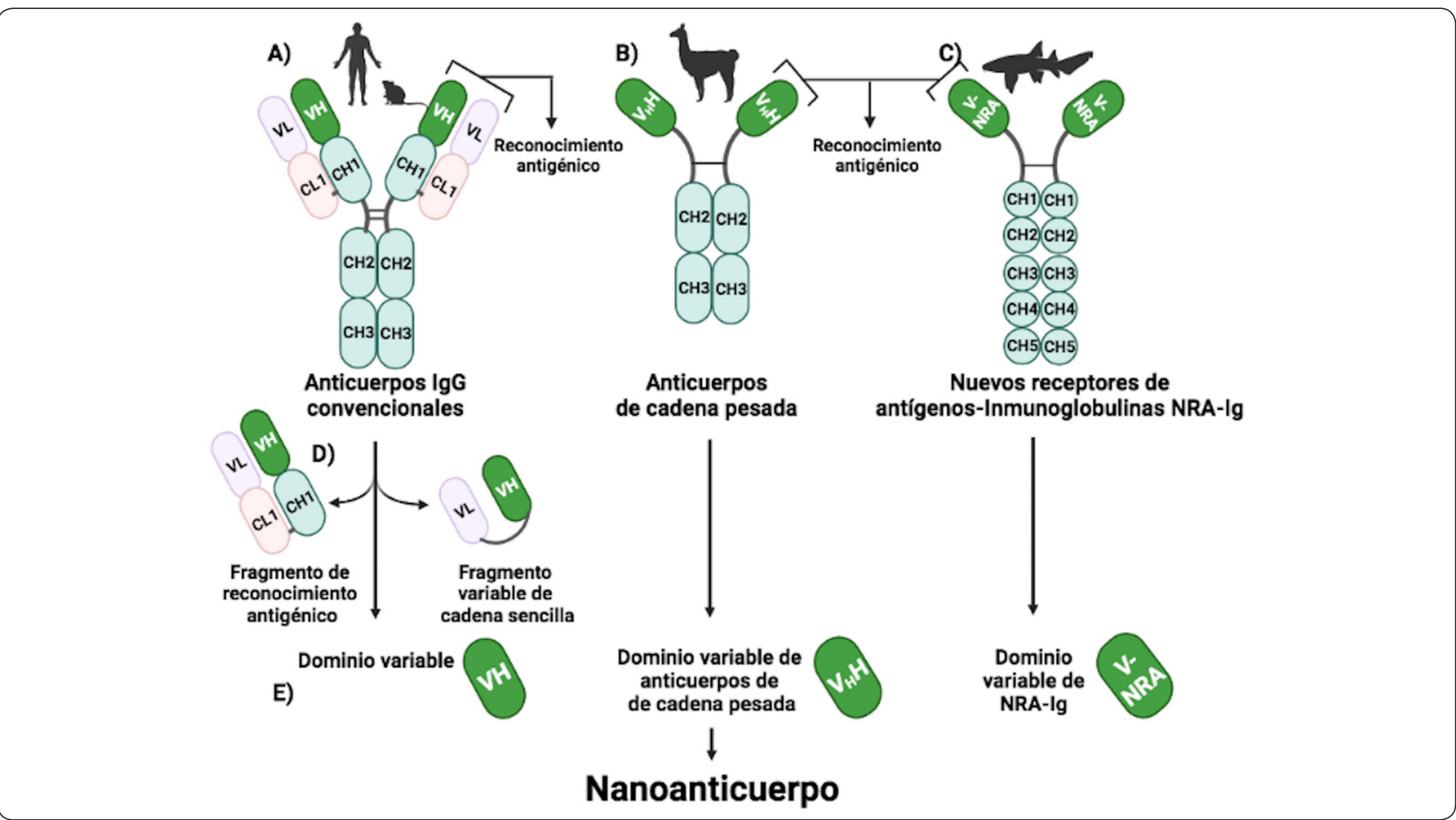

Figura 1. Esquema de anticuerpos convencionales y anticuerpos de cadena pesada. A) Anticuerpos tipo IgG heterodímero compuesto por dos cadenas pesadas (CH1, 2, 3 y un VH) y dos cadenas ligeras (CL1 y VL) y la región de reconocimiento antigénico (VH y VL). B) Anticuerpos de cadenas pesadas-homodímero $(C H 2,3)$ y la región de reconocimiento antigénico $\left(V_{H} H\right)$. C) Nuevo receptor antigénico de Inmunoglobulinas NRA-Ig-homodímero de dos cadenas pesadas (CH1-5) y la región de reconocimiento antigénico (V-NAR). D) fragmento de reconocimiento antigénico (CH1-CL1 y VH-VL) y fragmento variable de cadena sencilla (VH-VL). E) Dominios variables de reconocimiento. Abreviaturas: $\mathrm{CH}$ : Domino constante de cadena pesada, CL: Dominio constante de cadena ligera, $\mathrm{V}$ H/L: Dominio variable, $\mathrm{V}_{\mathrm{H}} \mathrm{H}$ : Dominio variable de anticuerpo de cadena pesada, V-NRA: Dominio variable del nuevo receptor antigénico. Elaboración personal ("Creado con Biorender.com").

Todos estos cambios de plegamiento y de secuencia, les brindan mayor solubilidad, además, dan lugar a una estructura alargada o esferoide relacionada con una mayor exposición del lugar específico de unión del anticuerpo con el antígeno, que aunado a su reducido tamaño, facilitan el reconocimiento de epítopos antigénicos que son de difícil acceso para los anticuerpos convencionales.

\section{Propiedades de los Nanoanticuerpos}

A pesar de su tamaño, tienen capacidad de unión a una amplia variedad de epítopos con afinidades reportadas en rangos de nanomolar (Sockolosky et al., 2016; Valdez-Cruz et al., 2021), se caracterizan por tener estabilidad conformacional, tolerancia térmica y a diferentes valores de $\mathrm{pH}$ (Cortez-Retamozo et al., 2004; Wang et al., 2014). Cuentan con la capacidad de replegarse después de estar expuestos a condiciones extremas como presión y agentes caotrópicos, conservando su solubilidad y capacidad de reconocimiento (Dumoulin et al., 2002).

Se ha evaluado su aplicación en especies diferentes a la de su origen, por ejemplo: en modelo murino de cáncer e infección parasitaria, con resultados prometedores (Cortez-Retamozo et al., 2004; Baral et al., 2006).

Su homología con los dominios variables de la cadena pesada de origen humano es alrededor del 95\% (Klarenbeek et al., 2015), además, la construcción de anticuerpos humanizados es otra estrategia que busca incrementar la posibilidad para una aplicación terapéutica (Vincke et al., 2009). La cristalización de estas moléculas ha permitido dilucidar el tipo de unión entre la molécula blanco y los Nac, y concluir que además de tener la capacidad de reconocimiento, tienen el potencial para ser usados como herramientas de estabilización estructural y capacidad neutralizante (Korotkov, Pardon, Steyaert \& Hol, 2009; Wrapp et al., 2020).

Su estructura monomérica les permite reconocer a los antígenos; sin embargo, es posible obtener estructuras multiméricas mediante técnicas de biología molecular aumentando su avidez y tiempo de vida media, por ejemplo, el formato bivalente permite incrementar el área de reconocimiento para antígenos multiméricos (Zhu et al., 2010) y el formato bi-específico para 
reconocer a dos secuencias antigénicas diferentes de manera simultánea (Els Conrath, Lauwereys, Wyns \& Muyldermans, 2001). También, es posible su conjugación con moléculas como fluorocromos, enzima peroxidasa de rábano, radionúclidos como el galio 68 y nanopartículas entre otros, lo que permite su aplicación hacia propósitos específicos (Cortez-Retamozo et al., 2004).

\section{DESARROLLO BIOTECNOLÓGICO EN SU PRODUCCIÓN Bibliotecas \\ Con el fin de obtener Nac con estabilidad y afinidad idóneas para su aplicación, la construcción de bibliotecas o bancos con anticuerpos de diferente naturaleza ha sido ampliamente utilizada (Liu et al., 2018).}

El desarrollo y selección de los Nac a partir de bibliotecas inmunes (Figura 2), implica la inmunización con el antígeno o molécula de interés a animales que desarrollen de manera natural anticuerpos de cadena pesada. Los pertenecientes a la familia Camelidae como llamas, alpacas y camellos, son ampliamente usados en la construcción de este tipo de bibliotecas.

Una vez que se completa el esquema de inmunización, el RNA mensajero (RNAm) extraído de los linfocitos de la sangre periférica, se transforma en DNA complementario (DNAc), que se usa como molde para amplificar específicamente la región variable de los anticuerpos. Estos fragmentos variables, tienen una longitud aproximada de 120 residuos de aminoácidos y están codificados por una secuencia génica de $\sim 360$ pares de bases $(\mathrm{pb})$. Posteriormente, estos fragmentos son ensamblados en vectores de clonación, por ejemplo, fagémidos, que se caracterizan por tener un origen de replicación para el plásmido y el fago, lo que permite el despliegue de los $N a c$ en una superficie fágica al exponerse a un fago adyuvante.

La resistencia a los antibióticos presentes en los vectores de clonación y la presencia de secuencias como las poli-histidinas o c-Myc presente en los Nac, son estrategias de diseño que permiten seleccionar a las clonas transformadas por los fagos e identificar a los Nac solubles respectivamente. Estos vectores de clonación, al actuar como vehículos de las secuencias altamente variables, se utilizan para transformar a bacterias como Escherichia coli TG1 (E. coli TG1), en una biblioteca o banco de Nanoanticuerpos.

Finalmente, mediante la interacción de una partícula fágica adyuvante y la biblioteca presente en bacterias, se induce el despliegue de los Nac en la superficie del fago, dando lugar a una plataforma idónea para la interacción con la molécula blanco (Salvador, Vilaplana \& Marco, 2019; Wang et al., 2016). El desarrollo de los $\mathrm{Nac}$ a partir de las bibliotecas inmunes, ofrece ventajas como la maduración de la afinidad inmune desarrollada

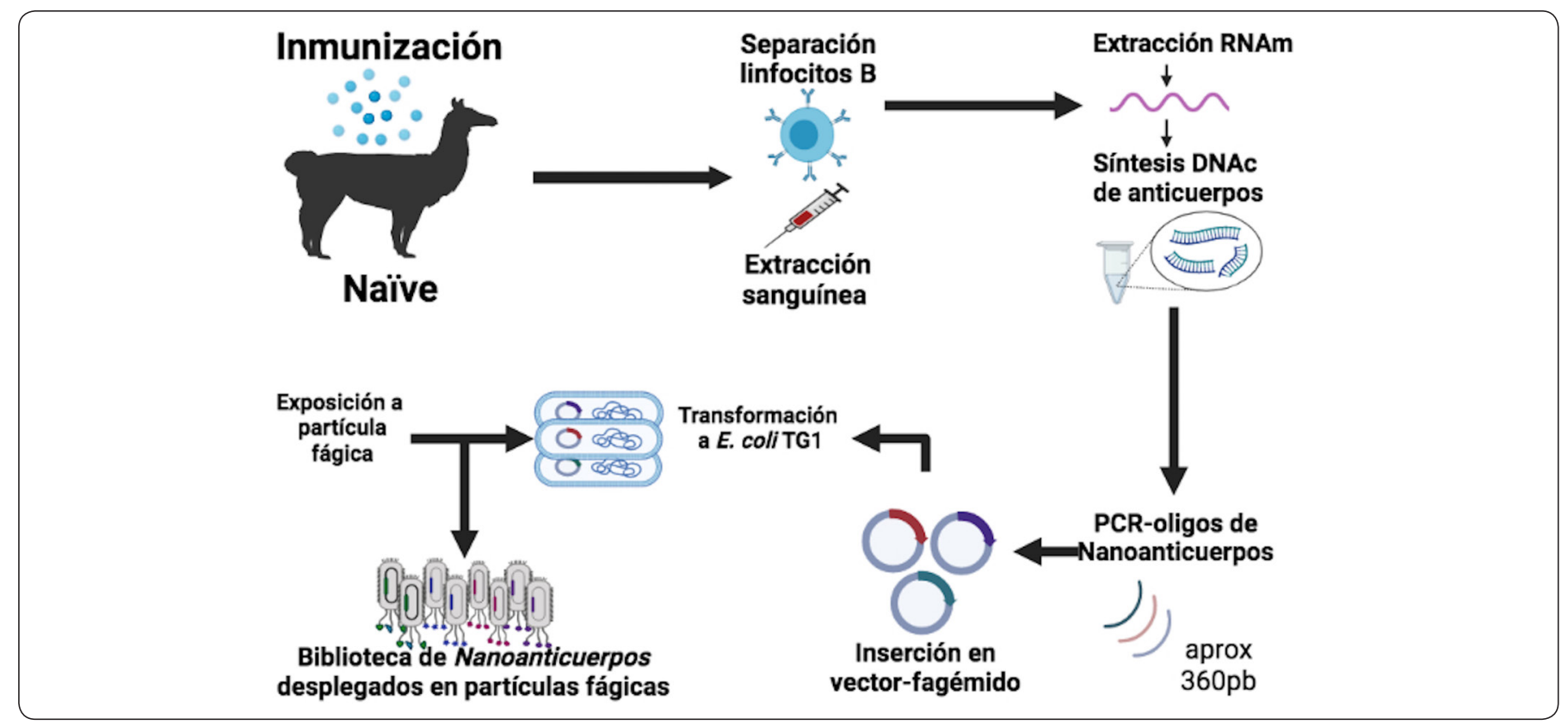

Figura 2. Esquema de la construcción de una biblioteca de Nanoanticuerpos usando partículas fágicas. La extracción de sangre puede ser de camélidos previamente inmunizados o no. Se separan los linfocitos B, se extrae el RNAm, y mediante RT-PCR se sintetiza DNAc, el cual se expone a oligos que permiten amplificar al Nac específicamente mediante PCR. Estas secuencias amplificadas son insertadas en vectores de clonación que son utilizados para transformar a $E$. coli TG1, dando lugar a la biblioteca de Nac. Finalmente esta es transfectada con una partícula fágica que permite el despliegue de Nac unidos a proteínas de la superficie fágica, representando una plataforma idónea para interaccionar con la molécula blanco. Abreviaturas: RT-PCR: Reverse Transcription Polymerase Chain Reaction, RNAm: RNA mensajero, DNAc: DNA complementario. Elaboración personal (“Creado con Biorender.com”). 
in vivo y un mayor grado de conservación en las secuencias de los fragmentos variables, en comparación con otros formatos, donde se requiere el acoplamiento entre las secuencias génicas de cadenas variables pesadas y ligeras mediante un péptido adicional (Muyldermans, 2013). Sin embargo, las limitantes son: por cada molécula blanco se requiere repetir todo el proceso y la naturaleza no inmunogénica o tóxica de algunas moléculas impide la inmunización.

La construcción de bibliotecas naïve, no inmunes, toma ventaja de la diversidad inmunológica natural del animal sin inmunización; sin embargo, una desventaja es que para obtener una mayor variedad de secuencias en los $N a c$, es necesario un mayor número de linfocitos, que en cantidad de sangre representa hasta un litro recolectado de diferentes individuos.

Otra alternativa, es la construcción de bibliotecas sintéticas y semisintéticas, construidas a partir de un menor volumen de sangre o de secuencias de anticuerpos (in silico). Mediante el uso de oligos aleatorios en PCR (del inglés Polymerase Chain Reaction) se modifican las secuencias de los CDRs, en especial la número tres, conservando los marcos de lectura canónicos de los dominios variables de la cadena pesada. Estas bibliotecas o bancos, cuentan con las características estructurales de los Nac y un alto número de secuencias diferentes de CDRs (Goldman et al., 2006). Representando así, una fuente de anticuerpos de un solo dominio y Nac que pueden ser dirigidos contra una amplia gama de antígenos, incluyendo aquellos con los que no es posible realizar una inmunización. Una ventaja es que no se requiere de todo el proceso de construcción para cada molécula blanco. Algunos autores nombran a los anticuerpos derivados de estas bibliotecas "Sybodies" en referencia a que son de origen $100 \%$ sintético.

Extrapolando estas estrategias metodológicas, es posible la construcción de bibliotecas de origen humano, aumentando la posibilidad de su aplicación terapéutica (Lee, Iorno, Sierro \&
Christ, 2007; Li et al., 2020). En la Tabla I se encuentran las principales características de las bibliotecas.

Un factor a tener en cuenta en la construcción de las bibliotecas, es la plataforma seleccionada para permitir la interacción $\mathrm{Nac}$ molécula blanco. Algunas de las opciones más exploradas son las partículas fágicas, las levaduras y los ribosomas como se describe a continuación.

Técnicas de despliegue de Nanoanticuerpos en fagos, ribosomas y levaduras

Existen varias técnicas de selección como: despliegue en fagos (phage display), en levaduras (yeast display), en ribosomas (ribosome display), en bacterias (bacterial display) y la técnica de CIS display, two hybrid, deep sequencing entre otros (Muyldermans, 2021).

La técnica de despliegue en fagos tiene como principio la asociación del genotipo de los bacteriófagos con su fenotipo, es decir, relaciona a la proteína expresada en la cápside viral con el gen que la codifica (Wu, Liu, Lu \& Wu, 2016). Es la técnica de selección más utilizada. Descrita en 1985 por el Dr. George P. Smith (Smith, 1985), acreedor en 2018 al premio Nobel de Química por su aporte a la biotecnología. El despliegue de los Nac en las partículas fágicas, se logra mediante su unión a proteínas de superficie, siendo la proteína III (pIII) la más utilizada, puesto que se encuentra ubicada en un extremo del fago, lo que permite una óptima interacción entre la molécula blanco y los Nac; su selección es llevada a cabo mediante múltiples rondas de exposición al antígeno (biopanning), y mediante la aplicación de estrategias metodológicas, es posible seleccionar a aquellos $N a c$-fagos con mayor afinidad. Finalizadas las rondas, se evalúa el reconocimiento de clonas individuales hacia la molécula de interés, con una selección individual para su posterior obtención como Nac soluble (Figura 3A).

Entre las ventajas del despliegue en fago se encuentran la

Tabla I. Bibliotecas de Nanoanticuerpos.

\begin{tabular}{|c|c|c|c|}
\hline \multirow{2}{*}{ Características } & \multicolumn{2}{|c|}{ Bibliotecas } & Nä̈ve \\
\cline { 2 - 4 } & Inmune & $\sim 10^{9}$ & No \\
\hline Variabilidad & $\sim 10^{6}$ & $>1 \mathrm{~L}$ & No \\
\hline Inmunización & Sí & No & sí \\
\hline Volumen de sangre & $0.05 \mathrm{~L}$ & Rango & Rango \\
\hline Origen humano & No & Micro/Nano Molar & Micro/pico Molar \\
\hline Afinidad $\mathrm{K}_{\mathrm{D}}$ & Rango & No limitada & No limitada \\
\hline Tipo de antígenos & Nano/pico Molar & Limitada & \\
\hline
\end{tabular}

L:litro; $\mathbf{K}_{\mathbf{D}}$ : constante de disociación. 


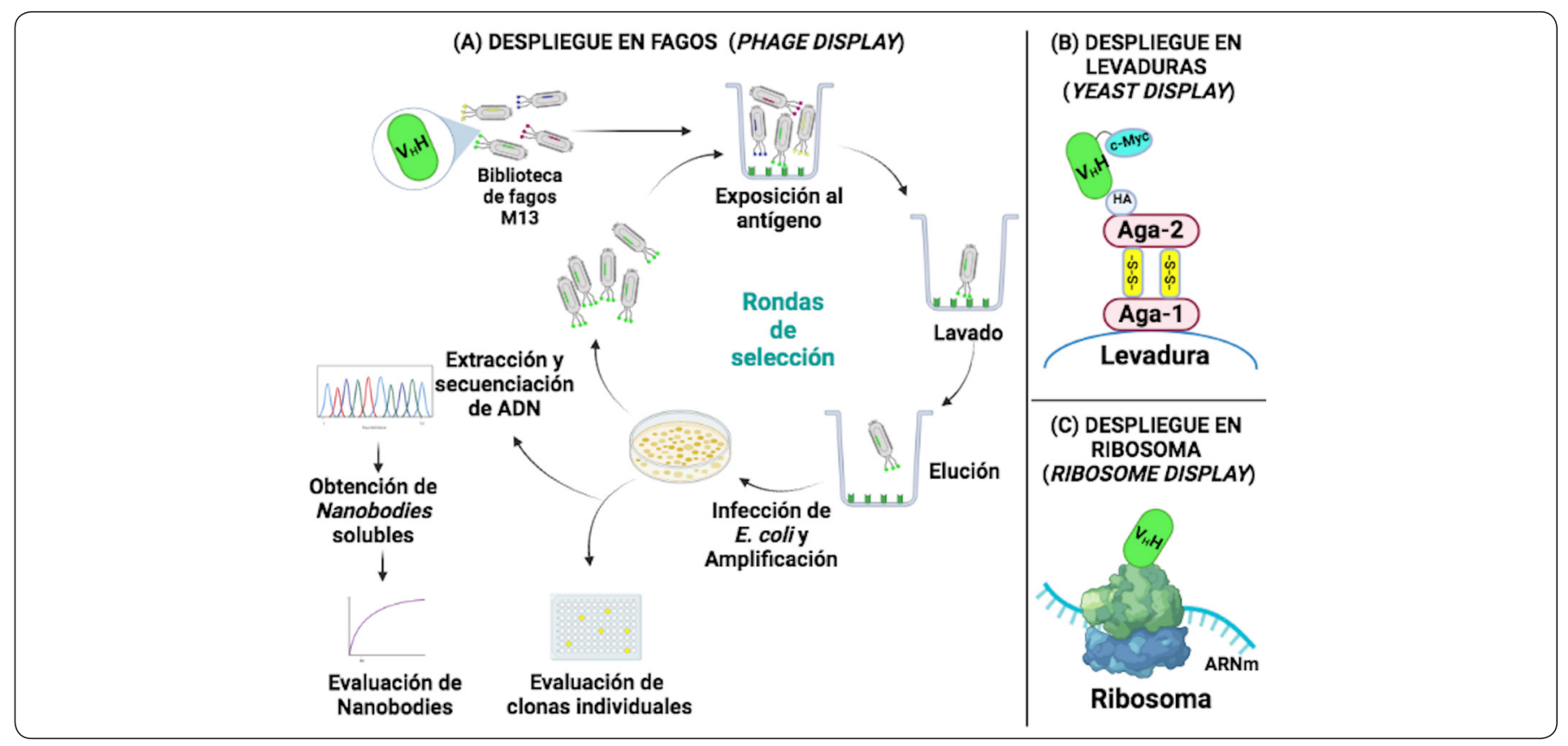

Figura 3. Despliegue en fago, levadura y ribosoma.A) Representación del proceso de selección del Nac (biopanning), evaluación, expresión, purificación y caracterización. B) Esquema de despliegue del Nac en el receptor Aga2 de la levadura. C) Complejo del ribosoma-RNAm$V_{H} H$. Elaboración personal ("Creado con Biorender.com").

tolerancia de los fagos a las altas temperaturas y ambientes ácidos, permitiendo seleccionar $\mathrm{Nac}$ con resistencia a estas condiciones (Muyldermans, 2013). Sin embargo, una desventaja es que al estar el Nac unido a la proteína III, existe la posibilidad de que ocurra un impedimento estérico (Silva et al., 2011).

Por otro lado, el despliegue en levadura es un sistema que utiliza el receptor de adhesión de $\alpha$-aglutinina de la superficie de la levadura para desplegar al Nac. Este sistema, usa el par de proteínas Aga1 y Aga2 unidas a la pared celular; la primera se une mediante los $\beta$-glucanos, mientras que la Aga 2 se une a Agal a través de puentes disulfuro. El anticuerpo de un solo dominio se encuentra fusionado a la proteína Aga2. La fusión sigue la vía secretora de las levaduras desde el retículo hasta la membrana plasmática (Salema \& Fernández, 2017). Para cuantificar el nivel de expresión del Nac, se utilizan epítopos de hemaglutinina (HA) y de c-Myc que son detectados por anticuerpos (Orcutt \& Wittrup, 2010) (Figura 3B). Una ventaja clara de esta técnica, es la posibilidad de caracterizar la constante de disociación $\left(\mathrm{K}_{\mathrm{D}}\right)$ del anticuerpo expresado en su superficie sin necesidad de expresarlo y purificarlo en su forma soluble (Gai \& Wittrup, 2007; Salema \& Fernández, 2017). Una desventaja es el tamaño relativamente pequeño de sus bibliotecas, comparado con otras técnicas de despliegue, debido a su limitada eficiencia durante la transformación (Orcutt \& Wittrup, 2010).

En la técnica de despliegue en ribosoma, el DNAde la biblioteca de interés es transcrito, produciendo RNAm utilizados para una traducción in vitro. Los ribosomas traducen a los RNAm (no tienen un codón de terminación) y sintetizan la secuencia polipeptídica codificada, para formar complejos de RNAmribosoma-proteína (Figura 3C) utilizados para una selección por exposición al antígeno de interés. Posteriormente, el RNAm de los complejos seleccionados es liberado y utilizado en una prueba de PCR con transcripción reversa, RT-PCR (del inglés Reverse Transcription Polymerase Chain Reaction), donde se amplifica y prepara para subsecuentes rondas de selección. Finalmente es posible la producción de anticuerpos de un solo dominio altamente específicos capaces de detectar al antígeno de interés (Galán et al., 2016). Al ser un ensayo sin células (cell-free), posee varias ventajas como la posibilidad de evaluar grandes bibliotecas $\left(10^{12}-10^{14}\right)$ en pocas reacciones de PCR y llevar a cabo la transcripción y la traducción acopladas o por separado, mientras que las desventajas de la técnica residen en la labilidad del RNAm y la necesidad de controlar variables como la presencia de enzimas RNAsas (Galán et al., 2016).

Porúltimo, la técnica de CIS display, es un sistema de selección de bibliotecas in vitro que aprovecha la capacidad de la proteína repA de unirse exclusivamente al DNA a partir del cual se ha expresado (propiedad llamada cis). Inicialmente se crea una biblioteca de péptidos muy diversa mediante la unión de fragmentos de DNA con secuencia aleatoria a fragmentos de DNA codificantes para la proteína repA. Posteriormente, se realiza una transcripción y traducción in vitro donde se obtienen un conjunto de complejos de DNA-repA-Nac, que pasan a través de rondas de selección por afinidad a ligandos de interés inmovilizados. A continuación, el DNA retenido es eluido y 
amplificado mediante PCR para formar una biblioteca de DNA lista para rondas de selección subsecuentes (tres a cinco rondas). Así, el DNA recuperado es clonado en un vector de expresión apropiado para la identificación de las secuencias peptídicas individuales (Odegrip et al., 2004; Mathonet, Ioannou, Betley \& Ullman, 2011).

\section{Sistemas de expresión de Nanoanticuerpos}

Los Nac se expresan en microorganismos, líneas celulares eucariotas y plantas (Muyldermans, 2013), por mencionar algunos ejemplos: las levaduras Saccharomyces cerevisiae y Pichia pastoris (Salema \& Fernández, 2017), la bacteria Corynebacterium glutamicum (Yim et al., 2015), el hongo Ustilago maydis (Terfrüchte et al., 2017), células de Spodoptera frugiperda (línea celular Sf9) infectadas con baculovirus (Shokrollahi, Habibi Anbouhi, Jahanian-Najafabadi, AliRahimi \& Behdani, 2021), u otros novedosos sistemas de expresión. Sin embargo, debido a sus altos rendimientos $\sim 2 \mathrm{mg} / 200$ $\mathrm{mL}$ (Ortega et al., 2020), simplicidad y bajo costo, E. coli es uno de los sistemas más utilizados, además, mediante herramientas de biología molecular es posible obtener a los Nac como proteínas solubles a partir del ambiente periplásmico bacteriano, optimizando la formación de los puentes disulfuro. $\mathrm{Su}$ purificación se lleva a cabo utilizando columnas cromatográficas con afinidad a los metales y de filtración en gel para obtener altos niveles de pureza. En caso de no utilizar algún marcaje presente en la secuencia de los Nac, también se purifican mediante la unión a la proteína A(Muyldermans, 2013; Ortega et al., 2020).

\section{APLiCACión de los NANOANTICUERPos}

$\mathrm{Su}$ tamaño, estabilidad, capacidad para replegarse, afinidad, especificidad y bajo costo de producción, convierte a los Nac en moléculas altamente versátiles (De Meyer, Muyldermans \& Depicker, 2014). Abordaremos su aplicación en tres áreas principalmente: cáncer, identificación de microorganismos y en la industria alimentaria.

\section{Nanoanticuerpos en cáncer}

Los Nac se han propuesto como candidatos alternativos para el diagnóstico del cáncer, gracias a sus propiedades y como consecuencia de que las técnicas utilizadas para su diagnóstico, como rayos $\mathrm{X}$, tomografías, resonancia magnética o ultrasonido, cuentan con baja resolución, visualización y altos costos (Yang \& Shah, 2020).

Actualmente las proyecciones de imágenes moleculares a través de las técnicas nucleares como PET(del inglés Positron Emission Tomography) y SPECT (del inglés Single-Photon Emission Computed Tomography), son ampliamente utilizadas en la detección de tumores, puesto que proporcionan una información completa del tejido tumoral y son no invasivas. Estas técnicas representan un escenario ideal para la aplicación de los Nac por su versatilidad, y por el extenso desarrollo de estos dirigidos hacia proteínas o receptores sobre-expresados en las células tumorales (Liu, Li, Jin \& Liu, 2021). Además, su tamaño y la facilidad para ser conjugados o acoplados a diferentes moléculas, optimizan la identificación y visualización del tejido de interés (Jovčevska \& Muyldermans, 2020).

Un gran número de $N a c$ se encuentran en etapas preclínicas y ensayos clínicos para ser utilizados como herramientas de diagnóstico, su acoplamiento con las técnicas PET y SPECT, van de la mano con el reconocimiento hacia marcadores moleculares como HER2 para cáncer de mama (Keyaerts et al., 2016; Xavier et al., 2016); el ligando PD-L1 como inhibidor de proliferación de linfocitos T (Xing et al., 2019; Gao et al., 2020), un dominio específico a fibronectina que detecta tumores primarios y sitios metastásicos (Jailkhani et al., 2019); o dirigido a VCAM como molécula de adhesión celular vascular (Zhang et al., 2018; Bridoux et al., 2020); por mencionar algunos.

La facilidad para ser conjugados con otros componentes, ha permitido explorar el potencial de los Nac como agentes terapéuticos contra el cáncer. Por ejemplo, en combinación con PDT (del inglés Photodynamic Therapy) la cual se basa en las propiedades foto-sensibilizantes de un compuesto químico para generar especies reactivas de oxígeno (ROS), produciendo la muerte celular de las células cancerígenas por las vías de la apoptosis y la necrosis (Deken, et al., 2020).

La adaptación de los Nac a células CAR-T (del inglés Chimeric Antigen Receptor-T Cells), se han evaluado siendo parte de su receptor de reconocimiento, o como moléculas de secreción con propiedades inmunomoduladoras para optimizar su efecto antitumoral (Xie et al., 2020). De igual manera, se ha explorado su aplicación al conjugarlos con diferentes fármacos, enzimas y toxinas (Kang et al., 2021). En la Tabla II, se muestran algunos ejemplos de estos $N a c$.

\section{Nanoanticuerpos para enfermedades Infecciosas}

La versatilidad de reconocimiento que tienen los $N a c$, permiten su aplicación en diferentes pasos durante un proceso infeccioso. La identificación del microorganismo y de los factores de virulencia como toxinas y proteínas de secreción, permiten su aplicación en las fases de diagnóstico, neutralización y tratamiento (Tabla II).

Han sido estudiados contra los patógenos de las vías respiratorias, y son candidatos gracias a su alta estabilidad para ser administrados mediante inhalación, facilitando su ingreso directamente al sitio de la infección (Respaud, Vecellio, Diot \& Heuzé-Vourc'h, 2015). Su potencial como moléculas neutralizantes dirigido contra SARS-CoV-2, causante de la pandemia actual, está siendo ampliamente explorado (ValdezCruz et al., 2021), con resultados prometedores. Su aplicación ha mostrado inhibir la entrada del virus in vitro (Wrapp et al., 2020), y disminución de la carga viral y protección al tejido afectado en modelo in vivo (Tabla II). 
Tabla II. Potencial de Aplicación Nanoanticuerpos.

\begin{tabular}{|c|c|c|c|c|}
\hline $\begin{array}{l}\text { Anticuerpos de } \\
\text { un solo dominio y } \\
\text { Nanoanticuerpos }\end{array}$ & Antígeno & $\begin{array}{c}\text { Metodología de } \\
\text { Selección- Despliegue en } \\
\text { fago }\end{array}$ & Potencial de aplicación & Referencias \\
\hline \multicolumn{5}{|c|}{ Cáncer } \\
\hline $\mathrm{Nb} 4$ & $\begin{array}{l}\text { Moléculas de adhesión } \\
\text { de células epiteliales }\end{array}$ & $\begin{array}{l}\text { Biblioteca inmune- } \\
\text { camello }\end{array}$ & Agente terapéutico & $\begin{array}{c}\text { Roshan et al., } \\
2021\end{array}$ \\
\hline $\mathrm{V}_{\mathrm{H}} \mathrm{H}-28 \mathrm{z}$ & RFCVE & $\begin{array}{l}\text { Biblioteca inmune- } \\
\text { camello }\end{array}$ & $\begin{array}{c}\text { Receptor de células T } \\
\text { terapéuticas }\end{array}$ & Hajari et al., 2019 \\
\hline Nb@IC-NPs & EGFR & $\begin{array}{l}\text { Biblioteca inmune- } \\
\text { camello }\end{array}$ & $\begin{array}{l}\text { Agente terapéutico dirigido } \\
\text { hacia cáncer de pulmón, } \\
\text { inhibe metástasis y } \\
\text { destruye tumor primario }\end{array}$ & Zhang et al., 2020 \\
\hline Viral GPCR US28 & GPCR & Biblioteca inmune-llama & $\begin{array}{c}\text { Agente terapéutico contra } \\
\text { glioblastoma }\end{array}$ & $\begin{array}{l}\text { De Groof et al., } \\
2019\end{array}$ \\
\hline anti-VEGF & VEGF & Biblioteca inmune-llama & $\begin{array}{l}\text { Agente terapéutico contra } \\
\text { cáncer metastásico }\end{array}$ & $\begin{array}{l}\text { Sadeghi et al., } \\
2020\end{array}$ \\
\hline NBPII-CAR & IL-2 y CD25 & Biblioteca inmune-llama & $\begin{array}{l}\text { Agente terapéutico contra } \\
\text { cáncer de próstata }\end{array}$ & $\begin{array}{c}\text { Hassani et al., } \\
2020\end{array}$ \\
\hline $\begin{array}{l}\text { Nanoanticuerpo- } \\
\text { (PS) }\end{array}$ & HER2 & Biblioteca inmune-llama & $\begin{array}{l}\text { Agente terapéutico contra } \\
\text { cáncer de mama HER2+ }\end{array}$ & Deken et al., 2020 \\
\hline \multicolumn{5}{|c|}{ Enfermedades de origen infeccioso } \\
\hline $\mathrm{V}_{\mathrm{H}} \mathrm{HA} 6$ & Proteína Env de VIH-1 & $\begin{array}{c}\text { Biblioteca inmune- } \\
\text { camello }\end{array}$ & $\begin{array}{l}\text { Tratamiento profiláctico en } \\
\text { mucosas }\end{array}$ & $\begin{array}{l}\text { Kalusche et al., } \\
2020\end{array}$ \\
\hline VH ab8 & RBD-SARS-CoV-2 & $\begin{array}{c}\text { Biblioteca de origen } \\
\text { humano }\end{array}$ & $\begin{array}{l}\text { Neutralización de infección } \\
\text { por SARS- Cov-2 }\end{array}$ & Li et al., 2020 \\
\hline $\begin{array}{l}\mathrm{Nb} 21 \\
\mathrm{Nb} 20\end{array}$ & RBD-SARS- CoV-2 & Biblioteca inmune-llama & $\begin{array}{l}\text { Neutralización de infección } \\
\text { por SARS- Cov-2 }\end{array}$ & Xiang et al., 2020 \\
\hline $\begin{array}{c}\text { 2TCE39 } \\
1 \text { TC39 }\end{array}$ & $\begin{array}{l}\text { Antígenos secreción } \\
\text { Toxocara canis (ASTC) }\end{array}$ & Biblioteca inmune-llama & $\begin{array}{c}\text { Identificación específica de } \\
\text { ASTC }\end{array}$ & $\begin{array}{l}\text { Morales et al., } \\
2019\end{array}$ \\
\hline $\begin{array}{c}10 \\
\text { Nanoanticuerpos }\end{array}$ & $\begin{array}{c}\text { Pf12p, proteína de } \\
\text { Plasmodium falciparum }\end{array}$ & Biblioteca inmune-alpaca & Identificación funcional & $\begin{array}{l}\text { Dietrich et al., } \\
2021\end{array}$ \\
\hline $2 \mathrm{R} 215$ & $\begin{array}{l}\text { Adhesina, factor de } \\
\text { colonización de E. coli. }\end{array}$ & Biblioteca inmune llama & Tratamiento profiláctico & $\begin{array}{l}\text { Amcheslavsky } \\
\text { et al., } 2021\end{array}$ \\
\hline $\begin{array}{c}\mathrm{V}_{\mathrm{H}} \mathrm{H}_{\mathrm{S}}: \mathrm{D} 12 / 11 \mathrm{~B} 5 \\
\mathrm{H} 11 / 20 / \mathrm{G} 12\end{array}$ & $\begin{array}{l}\text { BoNT/A1 } \\
\text { BoNT/B1 }\end{array}$ & Biblioteca inmune-alpaca & $\begin{array}{l}\text { Neutralización efecto } \\
\text { tóxico }\end{array}$ & Lam et al., 2020 \\
\hline $2 \mathrm{C}$ & $\begin{array}{l}\text { HLA-A*0201 } \\
\text { /Ag85Bp }{ }_{299-207} \text { de } \\
\text { Mycobacterium } \\
\text { tuberculosis }\end{array}$ & $\begin{array}{c}\text { Biblioteca de origen } \\
\text { humano }\end{array}$ & $\begin{array}{l}\text { Identificación de células } \\
\text { infectadas con } M . t b\end{array}$ & Ortega et al., 2020 \\
\hline \multicolumn{5}{|c|}{ Industria } \\
\hline $\mathrm{Nb} 16$ & Ara h $3 * *$ & $\begin{array}{c}\text { Biblioteca sintética } \\
\mathrm{V}_{\mathrm{H}} \mathrm{H}^{* * *} \\
\end{array}$ & $\begin{array}{c}\text { Identificación de alérgeno } \\
\text { en alimentos }\end{array}$ & Chen et al., 2019 \\
\hline $\begin{array}{l}\mathrm{V}_{2-5} \text { desplegado en } \\
\text { fago }\end{array}$ & $\begin{array}{l}\text { Aspergillus flavus/ } \\
\text { parasiticus }\end{array}$ & $\begin{array}{c}\text { Biblioteca } \\
\text { Inmune-alpaca }\end{array}$ & $\begin{array}{c}\text { Identificación de A. } \\
\text { flavus/parasiticus, en los } \\
\text { alimentos }\end{array}$ & Ren et al., 2020 \\
\hline
\end{tabular}


Tabla II. Potencial de Aplicación Nanoanticuerpos (continuación).

\begin{tabular}{|c|c|c|c|c|}
\hline $\begin{array}{c}\text { Anticuerpos de } \\
\text { un solo dominio y } \\
\text { Nanoanticuerpos }\end{array}$ & Antígeno & $\begin{array}{c}\text { Metodología de } \\
\text { Selección- Despliegue en } \\
\text { fago }\end{array}$ & Potencial de aplicación & Referencias \\
\hline $3 \mathrm{C} 3$ & $\begin{array}{c}\text { Toxina Cry1Ie de } \\
\text { Bacillus thuringiensis }\end{array}$ & $\begin{array}{c}\text { Biblioteca de origen } \\
\text { humano }\end{array}$ & $\begin{array}{l}\text { Detección de la toxina } \\
\text { (bioinsecticida) en } \\
\text { muestras agrícolas }\end{array}$ & Xu et al., 2017 \\
\hline $\begin{array}{l}\text { dAb8E-desplegado } \\
\text { en fago }\end{array}$ & $\begin{array}{l}\text { Péptido relacionado } \\
\text { con la producción } \\
\text { de anticuerpos en la } \\
\text { enfermedad celíaca }\end{array}$ & $\begin{array}{l}\text { Biblioteca de origen } \\
\text { humano }\end{array}$ & $\begin{array}{l}\text { Inmunoensayo para } \\
\text { detección de gluten en } \\
\text { alimentos }\end{array}$ & $\begin{array}{l}\text { García-García et } \\
\text { al., } 2020\end{array}$ \\
\hline $\mathrm{Nb} 13, \mathrm{Nb} 16, \mathrm{Nb} 22$ & $\begin{array}{l}\text { Salmonella enteritidis } \\
\text { inactivada en formalina }\end{array}$ & $\begin{array}{l}\text { Biblioteca inmune- } \\
\text { camello }\end{array}$ & $\begin{array}{c}\text { Detección de } \\
\text { S. enteritidis en leche }\end{array}$ & He et al., 2020 \\
\hline $\mathrm{C} 1$ & $\begin{array}{l}\text { Epítopo superficial de } \\
\text { Alexandrium minutum }\end{array}$ & Biblioteca inmune-llama & $\begin{array}{c}\text { Inmunosensor } \\
\text { electroquímico para } \\
\text { detección de la microalga } \\
\text { tóxica } A \text {. minutum }\end{array}$ & $\begin{array}{l}\text { Oloketuyi et al., } \\
\text { 2020; Mazzega et } \\
\text { al., } 2019\end{array}$ \\
\hline \multicolumn{5}{|c|}{ Aprobado por FDA } \\
\hline Caplacizumab & Factor Von Willebrand & Biblioteca inmune-llama & $\begin{array}{l}\text { Prevención de la } \\
\text { trombosis en púrpura } \\
\text { trombocitopénica }\end{array}$ & $\begin{array}{l}\text { Holliefield et al., } \\
\qquad 2020\end{array}$ \\
\hline
\end{tabular}

Abreviaturas: M. tb: Mycobacterium tuberculosis; RFCVE: Receptor del Factor de Crecimiento Vascular Endotelial; **ARAh3: Proteína Alergénica identificada en cacahuate; $* * \mathbf{V}_{\mathbf{H}} \mathbf{H}$ : dominio variable de anticuerpo de cadena pesada de camello-humanizado; EGFR: receptor del factor de crecimiento epidérmico; GPCR: receptor acoplado a proteínas G; HER2: receptor del factor de crecimiento epidérmico humano 2; IL-2: interleucina 2; VEGF: factor de crecimiento endotelial vascular; PS: photosensitizer (fotosensibilizador); BoNT/A1-B1: Neurotoxina Botulínica A1/B1; FDA: Food and Drug Administration.

Por sus características estructurales, ofrecen el reconocimiento necesario para diferenciar antígenos de secreción altamente similares entre especies de un mismo género, situación frecuente entre algunos parásitos causantes de zoonosis o infección en humanos (Morales et al., 2019).

Se han propuesto como vehículos de una toxina para inducir la muerte parasitaria (Baral et al., 2006), diagnóstico serológico y seguimiento de la infección (Pinto Torres et al., 2018; Deckers et al., 2009).

Su tamaño reducido también ha permitido evaluar estrategias para combatir microorganismos intracelulares, al dirigir su reconocimiento hacia sistemas de secreción ampliamente usados como factores de virulencia en bacterias (Zhang et al., 2021).

Diversos grupos de investigación han explorado el uso de bacterias que son parte de la microbiota como vehículos de los $\mathrm{Nac}$, expresados en superficie o secretados. Su aplicación va enfocada a neutralizar el efecto de las toxinas producidas por algunas bacterias como Clostridium difficile. Con el objetivo de proponer tratamientos que puedan ser administrados vía oral (Andersen et al., 2015) o aplicados en mucosas, actuando como barrera de ingreso a la infección (Kalusche et al., 2020).
Otra estrategia recientemente explorada, es su capacidad para identificar células infectadas por microorganismos persistentes como Mycobacterium tuberculosis, mediante la identificación de péptidos plegados con las moléculas de presentación antigénica clase I (Dass, Norazmi, Acosta, Sarmiento \& Tye, 2020; Ortega et al., 2020).

\section{Nanoanticuerpos para la Industria}

Por otro lado, la efectividad que ejercen los $\mathrm{Nac}$ al aplicarlos se extiende hasta la industria agrícola y de los alimentos, donde se han desarrollado como herramientas de identificación y detección de las toxinas producidas por microorganismos como las bacterias y los hongos principalmente. Por ejemplo, las micotoxinas de Aspergillus flavus (Ren et al., 2020), y la producida por Bacillus thuringiensis, que se han utilizado como un bio-insecticida efectivo para el control de plagas agrícolas (Xu et al., 2017). Para el año 2022, en Estados Unidos se espera el lanzamiento del primer biofungicida con el nombre "Biofun-1", el cual combina el reconocimiento de los Nac y antifúngicos contra Botrytis cinerea (Njeru \& Kusolwa, 2021). Empresas como Biotalys www.biotalys.com y el Institute for Agricultural, Fisheries and Food Research ILVO www.ilvo. vlaanderen.be, exploran el uso de los $\mathrm{Nac}$ en cultivos, con el objetivo de optimizar y mejorar la calidad de los alimentos. 
Los Nac también se han utilizado en inmunoensayos para detectar a patógenos transmitidos por alimentos (He et al., 2020; Hu et al., 2021), así como a los alérgenos del cacahuate (Chen et al., 2019) y de los cereales (García-García, Madrid, González, García \& Martín, 2020). Además, se han creado inmunosensores para identificar a las microalgas tóxicas que afectan a la industria pesquera y turística (Oloketuyi et al., 2020; Mazzega, Beran, Cabrini \& Marco, 2019).
Adicionalmente, los Nac también se han desarrollado como antivenenos, capaces de neutralizar o disminuir los efectos de las mordeduras de serpientes (Bailon et al., 2020) o de las picaduras de los arácnidos (Tabla II). En la Figura 4, se observa su potencial aplicación de forma esquemática.

Finalmente, el Nac bivalente humanizado Caplacizumab (Hollifield, Arnall \& Moore, 2020), fue el primer anticuerpo

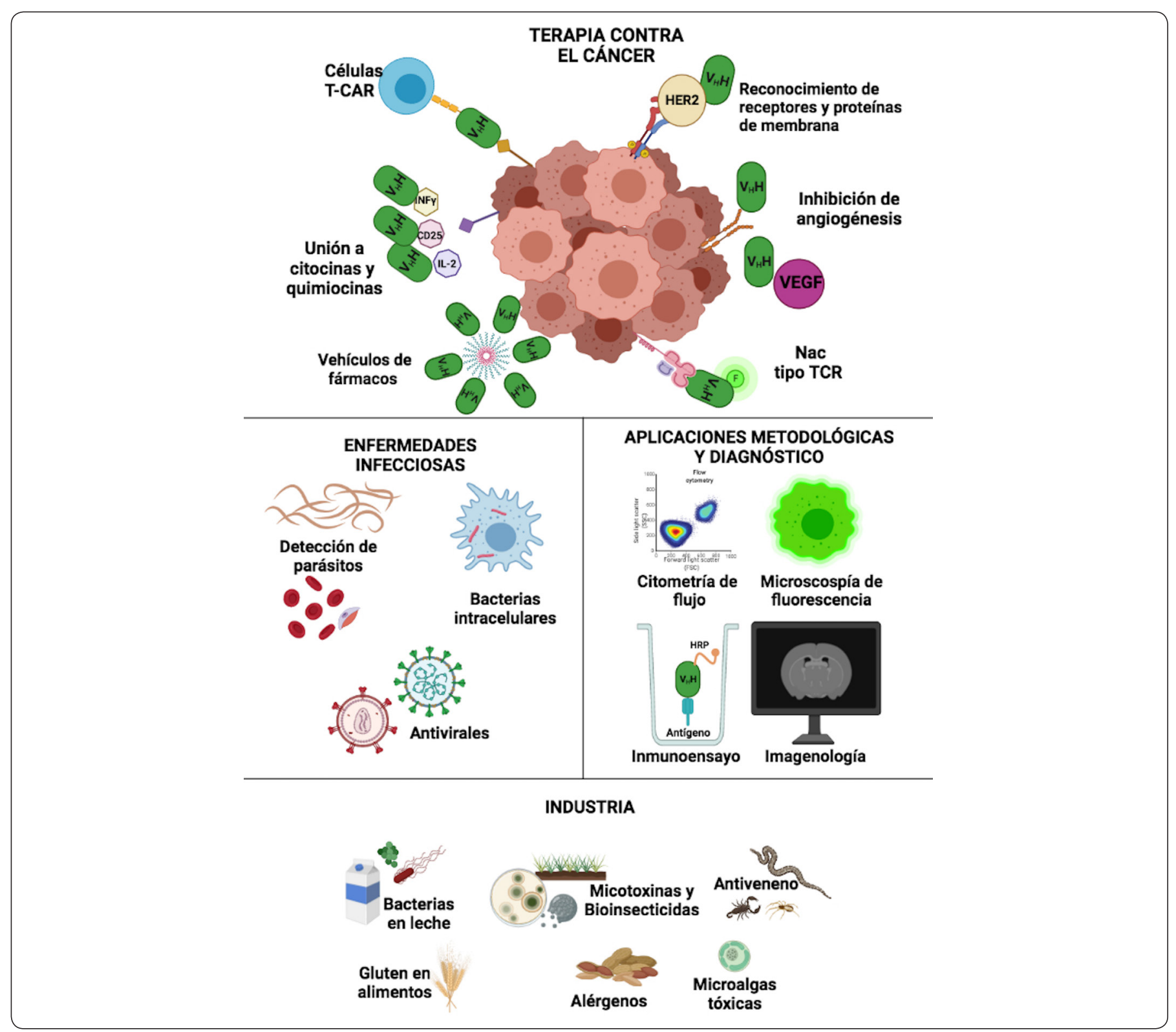

Figura 4. Esquema del potencial de aplicación de los Nanoanticuerpos: Sus características fisicoquímicas les permiten actuar como herramientas de estudio en el cáncer: mediante la identificación específica de tejido tumoral y su potencial inmunoterapéutico; en las enfermedades causadas por microorganismos: con diagnóstico y potencial neutralizante tanto del agente causal como de sus factores de virulencia; en el acoplamiento y optimización de técnicas como inmunoensayo, imagenología, citometría de flujo y microscopía de fluorescencia; y en el área industrial mediante la identificación de alérgenos, microorganismos y toxinas en alimentos. Abreviaturas: HER2: Receptor del Factor de Crecimiento Epidérmico humano 2; IFN- $\gamma$ : Interferón gamma; IL-2: interleucina 2; VEGF: factor de crecimiento endotelial vascular; $\mathrm{V}_{\mathrm{H}} \mathrm{H}$ : Nanoanticuerpos; TCR: Receptor de Células T. Elaboración personal ("Creado con Biorender.com"). 
con este formato en ser aprobado por la FDA (del inglés, Food and Drug Administration) y la EMA (del inglés, European Medicines Agency). Su mecanismo de acción consiste en impedir la interacción del factor von Willebrand y las plaquetas, para disminuir la formación de trombos. La administración subcutánea de Caplacizumab actúa como un tratamiento de la Púrpura Trombótica Trombocitopénica adquirida, que en combinación con la terapia actual, incrementó la resolución de la enfermedad y la disminución de los casos recurrentes (Jovčevska \& Muyldermans, 2020).

Los Nac, a pesar de ofrecer ventajas con respecto a los anticuerpos convencionales, también han mostrado ciertas limitaciones para su aplicación y desarrollo. Un estudio de biodistribución en ratones identificó su acumulación a nivel renal, lo que limitaría su uso para la evaluación de blancos en órganos cercanos al riñón, por ejemplo, el páncreas; sin embargo, el hígado y el bazo no presentaron problemas de acumulación (De Vos, Devoogdt, Lahoutte \& Muyldermans, 2013). Su formato monomérico es idóneo para la aplicación en estudios de imagenología; sin embargo, bajas concentraciones de su antígeno en sangre y su corto tiempo de vida, pueden ser factores que afecten de forma negativa su aplicación terapéutica (Jovčevska \& Muyldermans, 2020). Otro factor a tener en cuenta, es que los Nac de origen cien por ciento de procedencia humana, si bien brindan una mayor posibilidad de aplicación, no cuentan con las mismas cualidades estructurales típicas de los derivados de anticuerpos de cadena pesada. En cuanto a su desarrollo, se ha reportado la pérdida del reconocimiento hacia la molécula blanco después de separar a los Nac de su plataforma de selección (fago, levadura etc.), o debido a mutaciones presentes en su secuencia (Ortega et al., 2020). Disminuyendo las posibilidades de encontrar un $\mathrm{Nac}$ con el reconocimiento esperado.

\section{Conclusiones}

El avance acelerado en el desarrollo biotecnológico de los últimos años, y la necesidad de generar alternativas a los tratamientos y métodos de diagnóstico actuales, se acopla muy bien a las propiedades fisicoquímicas de los Nanoanticuerpos.

Los anticuerpos de un solo dominio o Nanoanticuerpos, ofrecen un panorama altamente versátil que permite su exploración y evaluación como herramientas de aplicación biomédica, industrial, biofarmacéutica, diagnóstica y terapéutica para enfermedades de diferentes orígenes.

\section{Agradecimientos}

Paola Andrea Ortega-Portilla estudiante del Programa de Doctorado en Ciencias Bioquímicas, de la Universidad Nacional Autónoma de México (UNAM) agradece la beca (707238) al Consejo Nacional de Ciencia y Tecnología (CONACYT). Enrique Wenceslao Coronado-Aceves agradece a la Dirección General de Asuntos del Personal Académico (DGAPA) de la UNAM por su beca para estancia posdoctoral.

\section{REFERENCIAS}

Amcheslavsky,A., Wallace, A. L., Ejemel, M., Li, Q., McMahon, C. T., Stoppato, M., Giuntini, S., Schiller, Z. A., Pondish, J. R., Toomey, J. R., Schneider, R. M., Meisinger, J., Heukers, R., Kruse, A. C., Barry, E. M., Pierce, B. G., Klempner, M. S., Cavacini, L. A. \& Wang, Y. (2021). Anti-CfaE nanobodies provide broad cross-protection against major pathogenic enterotoxigenic Escherichia coli strains, with implications for vaccine design. Scientific Reports, 11(1), 2751. DOI: https://doi.org/10.1038/s41598-021-81895-0

Andersen, K. K., Strokappe, N. M., Hultberg, A., Truusalu, K., Smidt, I., Mikelsaar, R. H., Mikelsaar, M., Verrips, T., Hammarström, L. \& Marcotte, H. (2015). Neutralization of Clostridium difficile Toxin B Mediated by Engineered Lactobacilli That Produce Single-Domain Antibodies. Infection and Immunity, 84(2), 395-406. DOI: https://doi. org/10.1128/IAI.00870-15

Bailon, H., Yaniro, V. O., Cáceres, O. A., Colque, E. G., Leiva, W. J., Padilla, C., Montejo, H., García, D., Galarza, M., Bonilla, C., Tintaya, B., Ricciardi, G., Smiejkowska, N., Romão, E., Vincke, C., Lévano, J., Celys, M., Lomonte, B. \& Muyldermans, S. (2020). Development of nanobodies against hemorrhagic and myotoxic components of Bothrops atrox snake venom. Frontiers in Immunology, 11, 655. DOI: https://doi.org/10.3389/fimmu.2020.00655

Baral, T. N., Magez, S., Stijlemans, B., Conrath, K., Vanhollebeke, B., Pays, E., Muyldermans, S. \& De Baetselier, P. (2006). Experimental therapy of African trypanosomiasis with a nanobody-conjugated human trypanolytic factor. Nature Medicine, 12(5), 580-584. DOI: https://doi.org/10.1038/nm1395

Bridoux, J., Neyt, S., Debie, P., Descamps, B., Devoogdt, N., Cleeren, F., Bormans, G., Broisat, A., Caveliers, V., Xavier, C., Vanhove, C. \& Hernot, S. (2020). Improved Detection of Molecular Markers of Atherosclerotic Plaques Using Sub-Millimeter PET Imaging. Molecules, 25(8), 1838. DOI: https://doi.org/10.3390/molecules25081838

Chen, F., Ma, H., Li, Y., Wang, H., Samad, A., Zhou, J., Zhu, L., Zhang, Y., He, J., Fan, X. \& Jin, T. (2019). Screening of Nanobody Specific for Peanut Major Allergen Ara h 3 by Phage Display. Journal of Agricultural and Food Chemistry, 67(40), 11219-11229. DOI: https://doi.org/10.1021/acs. jafc. $9 \mathrm{~b} 02388$

Cortez-Retamozo, V., Backmann, N., Senter, P. D., Wernery, U., De Baetselier, P., Muyldermans, S. \& Revets, H. (2004). Efficient cancer therapy with a nanobody-based conjugate. Cancer Research, 64(8), 2853-2857. DOI: https://doi. org/10.1158/0008-5472.can-03-3935

Dass, S. A., Norazmi, M. N., Acosta, A., Sarmiento, M. E. \& Tye, G. J. (2020). TCR-like domain antibody against Mycobacteriumtuberculosis(Mtb)heatshock proteinantigen presented by HLA-A*11 and HLA-A*24. International Journal of Biologicalmacromolecules, 155, 305-314. DOI: https://doi.org/10.1016/j.ijbiomac.2020.03.229 
De Groof, T., Mashayekhi, V., Fan, T. S., Bergkamp, N. D., Sastre Toraño, J., van Senten, J. R., Heukers, R., Smit, M. J. \& Oliveira, S. (2019). NanobodyTargeted Photodynamic Therapy Selectively Kills Viral GPCR-Expressing Glioblastoma Cells. Molecular Pharmaceutics, 16(7), 3145-3156. DOI: https://doi. org/10.1021/acs.molpharmaceut.9b00360

De Meyer, T., Muyldermans, S. \& Depicker, A. (2014). Nanobody-based products as research and diagnostic tools. Trends in Biotechnology, 32(5), 263-270. DOI: https://doi. org/10.1016/j.tibtech.2014.03.001

De Vos, J., Devoogdt, N., Lahoutte, T. \& Muyldermans, S. (2013). Camelid single-domain antibody-fragment engineering for (pre) clinical in vivo molecular imaging applications: adjusting the bullet to its target. Expert opinion on biological therapy, 13(8), 1149-1160. DOI: https://doi.org/10.1517/1 4712598.2013.800478

Deckers, N., Saerens, D., Kanobana, K., Conrath, K., Victor, B., Wernery, U., Vercruysse, J., Muyldermans, S. \& Dorny, P. (2009). Nanobodies, a promising tool for species-specific diagnosis of Taenia solium cysticercosis. International Journal for Parasitology, 39(5), 625-633. DOI: https:// doi.org/10.1016/j.ijpara.2008.10.012

Deken, M. M., Kijanka, M. M., Beltrán Hernández, I., Slooter, M. D., de Bruijn, H. S., van Diest, P. J., van Bergen En Henegouwen, P., Lowik, C., Robinson, D. J., Vahrmeijer, A. L. \& Oliveira, S. (2020). Nanobody-targeted photodynamic therapy induces significant tumor regression of trastuzumabresistant HER2-positive breast cancer, after a single treatment session. Journal of Controlled Release: Official Journal of the Controlled Release Society, 323, 269-281. DOI: https://doi.org/10.1016/j.jconrel.2020.04.030

Dietrich, M. H., Chan, L. J., Adair, A., Keremane, S., Pymm, P., Lo, A. W., Cao, Y. C. \& Tham, W. H. (2021). Nanobody generation and structural characterization of Plasmodium falciparum 6-cysteine protein Pf12p. The Biochemical Journal, 478(3), 579-595. DOI:https://doi.org/10.1042/ BCJ20200415

Dumoulin, M., Conrath, K., Van Meirhaeghe, A., Meersman, F., Heremans, K., Frenken, L. G., Muyldermans, S., Wyns, L. \& Matagne, A. (2002). Single-domain antibody fragments with high conformational stability. Protein Science, 11(3), 500-515. DOI: https://doi.org/10.1110/ps.34602

Els Conrath, K., Lauwereys, M., Wyns, L. \& Muyldermans, S. (2001). Camel single-domain antibodies as modular building units in bispecific and bivalent antibody constructs. The Journal of Biological Chemistry, 276(10), 7346-7350. DOI: https://doi.org/10.1074/jbc.M007734200

Gai, S. A. \& Wittrup, K. D. (2007). Yeast surface display for protein engineering and characterization. Current Opinion in Structural Biology, 17(4), 467-473. DOI: https://doi. org/10.1016/j.sbi.2007.08.012

Galán, A., Comor, L., Horvatić, A., Kuleš, J., Guillemin, N., Mrljak, V. \& Bhide, M. (2016). Library-based display technologies: where do we stand? Molecular BioSystems, 12(8), 2342-2358. DOI: https://doi. org/10.1039/C6MB00219F

Gao, H., Wu, Y., Shi, J., Zhang, X., Liu, T., Hu, B., Jia, B., Wan, Y., Liu, Z. \& Wang, F. (2020). Nuclear imagingguided PD-L1 blockade therapy increases effectiveness of cancer immunotherapy. Journal for Immunotherapy of Cancer, 8(2), e001156. DOI: http://dx.doi.org/10.1136/ jitc-2020-001156

García-García,A., Madrid, R., González, I., García, T. \& Martín, R. (2020). A novel approach to produce phage single domain antibody fragments for the detection of gluten in foods. Food Chemistry, 321, 126685. DOI: https://doi. org/10.1016/j.foodchem.2020.126685

Goldman, E. R., Anderson, G. P., Liu, J. L., Delehanty, J. B., Sherwood, L. J., Osborn, L. E., Cummins, L. B. \& Hayhurst, A. (2006). Facile generation of heat-stable antiviral and antitoxin single domain antibodies from a semisynthetic llama library. Analytical Chemistry, 78(24), 8245-8255. DOI: https://doi.org/10.1021/ac0610053

Govaert, J., Pellis, M., Deschacht, N., Vincke, C., Conrath, K., Muyldermans, S. \& Saerens, D. (2012). Dual beneficial effect of interloop disulfide bond for single domain antibody fragments. The Journal of Biological Chemistry, 287(3), 1970-1979.DOI: https://doi.org/10.1074/jbc.M111.242818

Greenberg, A. S., Avila, D., Hughes, M., Hughes, A., McKinney, E. C. \& Flajnik, M. F. (1995). A new antigen receptor gene family that undergoes rearrangement and extensive somatic diversification in sharks. Nature, 374(6518), 168-173. DOI: https://doi.org/10.1038/374168a0

Hajari Taheri, F., Hassani, M., Sharifzadeh, Z., Behdani, M., Arashkia, A. \& Abolhassani, M. (2019). T cell engineered with a novel nanobody-based chimeric antigen receptor against VEGFR2 as a candidate for tumor immunotherapy. IUBMB Life, 71(9), 1259-1267. DOI: https://doi. org/10.1002/iub.2019

Hamers-Casterman, C., Atarhouch, T., Muyldermans, S., Robinson, G., Hamers, C., Songa, E. B., Bendahman, N. \& Hamers, R. (1993). Naturally occurring antibodies devoid of light chains. Nature, 363(6428), 446-448. DOI: https:// doi.org/10.1038/363446a0

Harmsen, M. M., Ruuls, R. C., Nijman, I. J., Niewold, T. A., Frenken, L. G. \& de Geus, B. (2000). Llama heavy-chain $\mathrm{V}$ regions consist of at least four distinct subfamilies revealing novel sequence features. Molecular Immunology, 37(10), 579-590. DOI: https://doi.org/10.1016/s01615890(00)00081-x

Hassani, M., Hajari Taheri, F., Sharifzadeh, Z., Arashkia, A., Hadjati, J., van Weerden, W. M., Abdoli, S., Modarressi, M. H. \& Abolhassani, M. (2020). Engineered Jurkat Cells for Targeting Prostate-Specific Membrane Antigen on Prostate Cancer Cells by Nanobody-Based Chimeric Antigen Receptor. Iranian Biomedical Journal, 24(2), 81-88. DOI: https://doi.org/10.29252/ibj.24.2.81 
He, Y., Ren, Y., Guo, B., Yang, Y., Ji, Y., Zhang, D., Wang, J., Wang, Y. \& Wang, H. (2020). Development of a specific nanobody and its application in rapid and selective determination of Salmonella enteritidis in milk. Food Chemistry, 310, 125942. DOI: https://doi.org/10.1016/j. foodchem.2019.125942

Hollifield, A. L., Arnall, J. R. \& Moore, D. C. (2020). Caplacizumab: an anti-von Willebrand factor antibody for the treatment of thrombotic thrombocytopenic purpura. American journal of health-system pharmacy: AJHP. Official Journal of the American Society of HealthSystem Pharmacists, 77(15), 1201-1207. DOI: https://doi. org/10.1093/ajhp/zxaa151

Hu, Y., Sun, Y., Gu, J., Yang, F., Wu, S., Zhang, C., Ji., X., Lv, H., Muyldermans, S. \& Wang, S. (2021). Selection of specific nanobodies to develop an immunoassay detecting Staphylococcus aureus in milk. Food Chemistry, 353, 129481. DOI: https://doi.org/10.1016/j. foodchem.2021.129481

Jailkhani, N., Ingram, J. R., Rashidian, M., Rickelt, S., Tian, C., Mak, H., Jiang, Z., Ploegh, H. L. \& Hynes, R. O. (2019). Noninvasive imaging of tumor progression, metastasis, and fibrosis using a nanobody targeting the extracellular matrix. Proceedings of the National Academy of Sciences of the United States of America, 116(28), 14181-14190. DOI: https://doi.org/10.1073/pnas.1817442116

Jovčevska, I. \& Muyldermans, S. (2020). The Therapeutic Potential of Nanobodies. BioDrugs, 34, 11-26. DOI: https:// doi.org/10.1007/s40259-019-00392-Z

Kalusche, S., Vanshylla, K., Kleipass, F., Gruell, H., Müller, B., Zeng, Z., Koch, K., Stein, S., Marcotte, H., Klein, F. \& Dietrich, U. (2020). Lactobacilli Expressing Broadly Neutralizing Nanobodies against HIV-1 as Potential Vectors for HIV-1 Prophylaxis? Vaccines, 8(4), 758. DOI: https:// doi.org/10.3390/vaccines 8040758

Kang, W., Ding, C., Zheng, D., Ma, X., Yi, L., Tong, X., Wu, C., Xue, C., Yu, Y. \& Zhou, Q. (2021). Nanobody Conjugates for Targeted Cancer Therapy and Imaging. Technology in cancer research \& Treatment, 20, 15330338211010117. DOI: https://doi.org/10.1177/15330338211010117

Keyaerts, M., Xavier, C., Heemskerk, J., Devoogdt, N., Everaert, H., Ackaert, C., Vanhoeij, M., Duhoux, F. P., Gevaert, T., Simon, P., Schallier, D., Fontaine, C., Vaneycken, I., Vanhove, C., De Greve, J., Lamote, J., Caveliers, V. \& Lahoutte, T. (2016). Phase I Study of 68Ga-HER2Nanobody for PET/CT Assessment of HER2 Expression in Breast Carcinoma. Journal of Nuclear Medicine: Official Publication, Society of Nuclear Medicine, 57(1), 27-33. DOI: https://doi.org/10.2967/jnumed.115.162024

Klarenbeek, A., El Mazouari, K., Desmyter, A., Blanchetot, C., Hultberg, A., de Jonge, N., Roovers, R. C., Cambillau, C., Spinelli, S., Del-Favero, J., Verrips, T., de Haard, H. J. \& Achour, I. (2015). Camelid Ig V genes reveal significant human homology not seen in therapeutic target genes, providing for a powerful therapeutic antibody platform. $m A b s, 7(4), 693-706$. DOI: https://doi.org/10.1080/1942 0862.2015 .1046648

Köhler, G. \& Milstein, C. (1975). Continuous cultures of fused cells secreting antibody of predefined specificity. Nature, 256(5517), 495-497. DOI: https://doi. org/10.1038/256495a0

Korotkov, K. V., Pardon, E., Steyaert, J. \& Hol, W. G. (2009). Crystal structure of the N-terminal domain of the secretin GspD from ETEC determined with the assistance of a nanobody. Structure, 17(2), 255-265. DOI: https://doi. org/10.1016/j.str.2008.11.011

Lam, K. H., Tremblay, J. M., Vazquez-Cintron, E., Perry, K., Ondeck, C., Webb, R. P., McNutt, P. M., Shoemaker, C. B. \& Jin, R. (2020). Structural Insights into Rational Design of Single-Domain Antibody-Based Antitoxins against Botulinum Neurotoxins. Cell Reports, 30(8), 2526-2539. e6. DOI: https://doi.org/10.1016/j.celrep.2020.01.107

Lee, C. M., Iorno, N., Sierro, F. \& Christ, D. (2007). Selection of human antibody fragments by phage display. Nature Protocols, 2(11), 3001-3008. DOI: https://doi.org/10.1038/ nprot. 2007.448

Li, W., Schäfer, A., Kulkarni, S. S., Liu, X., Martinez, D. R., Chen, C., Sun, Z., Leist, S. R., Drelich, A., Zhang, L., Ura, M. L., Berezuk, A., Chittori, S., Leopold, K., Mannar, D., Srivastava, S. S., Zhu, X., Peterson, E. C., Tseng, C. T., Mellors, J. W. \& Dimitrov, D. S. (2020). High Potency of a Bivalent Human VH Domain in SARS-CoV-2 Animal Models. Cell, 183(2), 429-441.e16. DOI: https://doi. org/10.1016/j.cell.2020.09.007

Liu, W., Song, H., Chen, Q., Yu, J., Xian, M., Nian, R. \& Feng, D. (2018). Recent advances in the selection and identification of antigen-specific nanobodies. Molecular Immunology, 96, 37-47. DOI: 10.1016/j.molimm.2018.02.012

Liu, M., Li, L., Jin, D. \& Liu, Y. (2021). Nanobody-A versatile tool for cancer diagnosis and therapeutics. Wiley interdisciplinary reviews. Nanomedicine and Nanobiotechnology, e1697. Advance online publication. DOI: 10.1002/wnan.1697

Mathonet, P., Ioannou, Avgousta, Betley, Jason \& Ullman, C. (2011). CIS display, a DNA-based in vitro selection technology for therapeutic peptides. Chimica Oggi Chemistry Today, 29, 10-12. DOI: https://doi.org/10.1073/ pnas.0400219101

Mazzega, E., Beran, A., Cabrini, M. \& de Marco, A. (2019). In vitro isolation of nanobodies for selective Alexandrium minutum recognition: a model for convenient development of dedicated immuno-reagents to study and diagnostic toxic unicellular algae. Harmful Algae, 82, 44-51. DOI: https:// doi.org/10.1016/j.hal.2019.01.002

Morales-Yanez, F. J., Sariego, I., Vincke, C., HassanzadehGhassabeh, G., Polman, K. \& Muyldermans, S. (2019). An innovative approach in the detection of Toxocara canis excretory/secretory antigens using specific nanobodies. 
International Journal for Parasitology, 49(8), 635-645. DOI: https://doi.org/10.1016/j.ijpara.2019.03.004

Muyldermans, S., Atarhouch, T., Saldanha, J., Barbosa, J. A. \& Hamers, R. (1994). Sequence and structure of $\mathrm{VH}$ domain from naturally occurring camel heavy chain immunoglobulins lacking light chains. Protein Engineering, 7(9), 1129-1135. DOI: https://doi. org/10.1093/protein/7.9.1129

Muyldermans S. (2013). Nanobodies: natural singledomain antibodies. Annual Review of Biochemistry, 82, 775-797. DOI: https://doi.org/10.1146/annurevbiochem-063011-092449

Muyldermans, S. (2021). A guide to: generation and design of nanobodies. The FEBS Journal, 288(7), 2084-2102. DOI: https://doi.org/10.1111/febs. 15515

Njeru, F. N., \& Kusolwa, P. M. (2021). Nanobodies: their potential for applications in biotechnology, diagnosis and antiviral properties in Africa; focus on application in agriculture. Biotechnology \& Biotechnological Equipment, 35(1), 1331-1342. DOI: https://doi.org/10.1080/1310281 8.2021 .1974943

Nuttall, S. D., Krishnan, U. V., Hattarki, M., De Gori, R., Irving, R. A. \& Hudson, P. J. (2001). Isolation of the new antigen receptor from wobbegong sharks, and use as a scaffold for the display of protein loop libraries. Molecular Immunology, 38(4), 313-326. DOI: https://doi.org/10.1016/ s0161-5890(01)00057-8

Odegrip, R., Coomber, D., Eldridge, B., Hederer, R., Kuhlman, P. A., Ullman, C., FitzGerald, K. \& McGregor, D. (2004). CIS display: in vitro selection of peptides from libraries of protein-DNA complexes. Proceedings of the National Academy of Sciences, 101(9), 2806-2810. DOI: https://doi. org/10.1073/pnas.0400219101

Oloketuyi, S., Mazzega, E., Zavašnik, J., Pungjunun, K., Kalcher, K., De Marco, A. \& Mehmeti, E. (2020). Electrochemical immunosensor functionalized with nanobodies for the detection of the toxic microalgae Alexandrium minutum using glassy carbon electrode modified with gold nanoparticles. Biosensors a d Bioelectronics, 154, 112052. DOI: https://doi.org/10.1016/j.bios.2020.112052

Orcutt, K. D. \& Wittrup, K. D. (2010). Yeast display and selections. In Antibody engineering (pp. 207-233). Springer, Berlin, Heidelberg. DOI: https://doi.org/10.1007/978-3642-01144-3 15

Ortega, P. A., Silva-Miranda, M., Torres-Larios, A., CamposChávez, E., Franken, K., Ottenhoff, T., Ivanyi, J. \& Espitia, C. (2020). Selection of a Single Domain Antibody, Specific for an HLA-Bound Epitope of the Mycobacterial Ag85B Antigen. Frontiers in Immunology, 11, 577815. DOI: https:// doi.org/10.3389/fimmu.2020.577815

Padlan, E. A. (1994). Anatomy of the antibody molecule. Molecular Immunology, 31(3), 169-217. DOI: 10.1016/0161-5890(94)90001-9
Pinto Torres, J. E., Goossens, J., Ding, J., Li, Z., Lu, S., Vertommen, D., Naniima, P., Chen, R., Muyldermans, S., Sterckx, Y. G. \& Magez, S. (2018). Development of a Nanobody-based lateral flow assay to detect active Trypanosoma congolense infections. Scientific Reports, 8(1), 9019. DOI:10.1038/s41598-018-26732-7

Ren, X., Yue, X., Mwakinyali, S. E., Zhang, W., Zhang, Q. \& Li, P. (2020). Small Molecular Contaminant and Microorganism Can Be Simultaneously Detected Based on Nanobody-Phage: Using Carcinogen Aflatoxin and Its Main Fungal Aspergillus Section Flavi spp. in Stored Maize for Demonstration. Frontiers in Microbiology, 10, 3023. DOI: https://doi.org/10.3389/fmicb.2019.03023

Respaud, R., Vecellio, L., Diot, P. \& Heuzé-Vourc'h, N. (2015). Nebulization as a delivery method for mAbs in respiratory diseases. Expert Opinion on Drug Delivery, 12(6), 1027-1039. DOI:10.1517/17425247.2015.999039

Roshan, R., Naderi, S., Behdani, M., Cohan, R. A., Ghaderi, H., Shokrgozar, M. A., Golkar, M. \& KazemiLomedasht, F. (2021). Isolation and characterization of nanobodies against epithelial cell adhesion molecule as novel theranostic agents for cancer therapy. Molecular Immunology, 129, 70-77. DOI: https://doi.org/10.1016/j. molimm.2020.10.021

Sadeghi, A., Behdani, M., Muyldermans, S., Habibi-Anbouhi, M. \& Kazemi-Lomedasht, F. (2020). Development of a mono-specific anti-VEGF bivalent nanobody with extended plasma half-life for treatment of pathologic neovascularization. Drug Testing and Analysis, 12(1), 92-100. DOI: 10.1002/dta.2693

Salema, V. \& Fernández, L. Á. (2017). Escherichia coli surface display for the selection of nanobodies. Microbial Biotechnology, 10(6), 1468-1484. DOI: https://doi. org/10.1111/1751-7915.12819

Salvador, J. P., Vilaplana, L. \& Marco, M. P. (2019). Nanobody: outstanding features for diagnostic and therapeutic applications. Analytical and Bioanalytical Chemistry, 411(9), 1703-1713. DOI: https://doi.org/10.1007/s00216019-01633-4

Shokrollahi, N., Habibi Anbouhi, M., Jahanian-Najafabadi, A., AliRahimi, E. \& Behdani, M. (2021). Expressing of Recombinant VEGFR2-specific Nanobody in Baculovirus Expression System. Iranian Journal of Biotechnology, 19(1), 60-66.DOI: https://doi.org/10.30498/IJB.2021.2783

Silva, S., Maghalaes, A. A., De Castro, S. S., Zurita-Turk, M., Goulart, L. R., Miyoshi,A.\&Azevedo, V.(2011). The phage display technique: advantages and recent patents. Recent Patents on DNA \& Gene Sequences, 5, 136-148. DOI:

$10.2174 / 187221511796392060$

Singh, S., Kumar, N. K., Dwiwedi, P., Charan, J., Kaur, R., Sidhu, P. \& Chugh, V. K. (2018). Monoclonal Antibodies: A Review. Current Clinical Pharmacology, 13(2), 85-99. DOI: $10.2174 / 1574884712666170809124728$ 
Siontorou, C. G. (2013). Nanobodies as novel agents for disease diagnosis and therapy. International Journal of Nanomedicine, 8,4215-4227.DOI:https://doi.org/10.2147/ IJN.S39428

Smith, G.P.(1985). Filamentous fusion phage: novel expression vectors that display cloned antigens on the virion surface. Science, 228(4705), 1315-1317. DOI: https://doi. org/10.1126/science.4001944

Sockolosky, J. T., Dougan, M., Ingram, J. R., Ho, C. C., Kauke, M. J., Almo, S. C., Ploegh, H. L. \& Garcia, K. C. (2016). Durable antitumor responses to CD47 blockade require adaptive immune stimulation. Proceedings of the National Academy of Sciences of the United States of America, 113(19), 2646-2654. DOI: https://doi.org/10.1073/ pnas. 1604268113

Stanfield, R. L., Dooley, H., Verdino, P., Flajnik, M. F. \& Wilson, I. A. (2007). Maturation of shark single-domain (IgNAR) antibodies: evidence for induced-fit binding. Journal of Molecular Biology, 367(2), 358-372. DOI: https://doi. org/10.1016/j.jmb.2006.12.045

Terfrüchte, M., Reindl, M., Jankowski, S., Sarkari, P., Feldbrügge, M. \& Schipper, K. (2017). Applying unconventional secretion in Ustilago maydis for the export of functional nanobodies. International Journal of Molecular Sciences, 18(5), 937. DOI: https://doi.org/10.3390/ijms 18050937

Valdez-Cruz, N. A., García-Hernández, E., Espitia, C., Cobos-Marín, L., Altamirano, C., Bando-Campos, C. G., Cofas-Vargas, L. F., Coronado-Aceves, E. W., GonzálezHernández, R. A., Hernández-Peralta, P., Juárez-López, D., Ortega-Portilla, P.A., Restrepo-Pineda, S.,Zelada-Cordero, P. \& Trujillo-Roldán, M. A. (2021). Integrative overview of antibodies against SARS-CoV-2 and their possible applications in COVID-19 prophylaxis and treatment. Microbial Cell Factories, 20(1), 88. DOI: https://doi. org/10.1186/s12934-021-01576-5

Vincke, C., Loris, R., Saerens, D., Martinez-Rodriguez, S., Muyldermans, S. \& Conrath, K. (2009). General strategy to humanize a camelid single-domain antibody and identification of a universal humanized nanobody scaffold. The Journal of Biological Chemistry, 284(5), 3273-3284. DOI: https://doi.org/10.1074/jbc.M806889200

Wang, J., Bever, C. R., Majkova, Z., Dechant, J. E., Yang, J., Gee, S. J., Xu, T. \& Hammock, B. D. (2014). Heterologous antigen selection of camelid heavy chain single domain antibodies against tetrabromobisphenol A. Analytical Chemistry, 86(16), 8296-8302. DOI: https://doi. org/10.1021/ac5017437

Wang, Y., Fan, Z., Shao, L., Kong, X., Hou, X., Tian, D., Sun, Y., Xiao, Y. \& Yu, L. (2016). Nanobody-derived nanobiotechnology tool kits for diverse biomedical and biotechnology applications. International Journal of Nanomedicine, 11, 3287-3303. DOI: https://doi. org/10.2147/IJN.S107194

Wrapp, D., De Vlieger, D., Corbett, K. S., Torres, G. M., Wang,
N., Van Breedam, W., Roose, K., van Schie, L., VIB-CMB COVID-19 Response Team, Hoffmann, M., Pöhlmann, S., Graham, B. S., Callewaert, N., Schepens, B., Saelens, X. \& McLellan, J. S. (2020). Structural Basis for Potent Neutralization of Betacoronaviruses by Single-Domain CamelidAntibodies. Cell, 181(6), 1436-1441.DOI: https:// doi.org/10.1016/j.cell.2020.04.031

Wu, C. H., Liu, I. J., Lu, R. M. \& Wu, H. C. (2016). Advancement and applications of peptide phage display technology in biomedical science. Journal of Biomedical Science, 23: 8 . DOI: https://doi.org/10.1186/s12929-016-0223-x

Xavier, C., Blykers, A., Vaneycken, I., D'Huyvetter, M., Heemskerk, J., Lahoutte, T. \& Caveliers, V. (2016). 18F-nanobody for PET imaging of HER2 overexpressing tumors. Nuclear Medicine and Biology, 43(4), 247-252. DOI: https://doi.org/10.1016/j.nucmedbio.2016.01.002

Xiang, Y., Nambulli, S., Xiao, Z., Liu, H., Sang, Z., Duprex, W. P., Schneidman-Duhovny, D., Zhang, C. \& Shi, Y. (2020). Versatile and multivalent nanobodies efficiently neutralize SARS-CoV-2. Science (New York, N.Y.), 370(6523), 1479-1484. DOI: https://doi.org/10.1126/ science.abe 4747

Xie, Y. J., Dougan, M., Ingram, J. R., Pishesha, N., Fang, T., Momin, N. \& Ploegh, H. L. (2020). Improved Antitumor Efficacy of Chimeric Antigen Receptor T Cells that Secrete Single-Domain Antibody Fragments. Cancer Immunology Research, 8(4), 518-529. DOI: https://doi. org/10.1158/2326-6066.CIR-19-0734

Xing, Y., Chand, G., Liu, C., Cook, G., O’Doherty, J., Zhao, L., Wong, N., Meszaros, L. K., Ting, H. H. \& Zhao, J. (2019). Early Phase I Study of a ${ }^{99 m} \mathrm{Tc}-L a b e l e d$ Anti-Programmed Death Ligand-1 (PD-L1) Single-Domain Antibody in SPECT/CTAssessment of PD-L1 Expression in Non-Small Cell Lung Cancer. Journal of Nuclear Medicine: Official Publication, Society of Nuclear Medicine, 60(9), 12131220. DOI: https://doi.org/10.2967/jnumed.118.224170

Xu, C., Liu, X., Zhang, C., Zhang, X., Zhong, J., Liu, Y., Hu, X.,Lin, M. \& Liu, X. (2017). Establishment of a sensitive time-resolved fluoroimmunoassay for detection of Bacillus thuringiensis Cry1Ie toxin based nanobody from a phage display library. Analytical Biochemistry, 518, 53-59. DOI: https://doi.org/10.1016/j.ab.2016.11.006

Yang E. Y. \& Shah K. (2020). Nanobodies: Next Generation of Cancer Diagnostics and Therapeutics. Frontiers in Oncology 10:1182. DOI: https://doi.org/10.3389/fonc.2020.01182

Yim, S. S., Choi, J. W., Lee, R. J., Lee, Y. J., Lee, S. H., Kim, S. Y, \& Jeong, K. J. (2015). Development of a new platform for secretory production of recombinant proteins in Corynebacterium glutamicum. Biotechnology and Bioengineering, 113(1), 163-172. DOI: https://doi. org/10.1002/bit.25692

Zhang, X., Hu, F., Liu, C., Yin, L., Zhang, Y., Zhang, Y. \& Lan, X. (2018). Evaluation of ${ }^{99 m}$ Tc-HYNIC-VCAM$1_{\mathrm{scFv}}$ as a Potential Qualitative and Semiquantitative 
Probe Targeting Various Tumors. Contrast Media \& Molecular Imaging, 2018, 7832805. DOI: https://doi. org/10.1155/2018/7832805

Zhang, Q., Wu, L., Liu, S., Chen, Q., Zeng, L., Chen, X. \& Zhang, Q. (2020). Targeted nanobody complex enhanced photodynamic therapy for lung cancer by overcoming tumor microenvironment. Cancer Cell International, 20(1), 570. DOI: https://doi.org/10.1186/s12935-020-01613-0

Zhang, W., Lin, M., Yan, Q., Budachetri, K., Hou, L., Sahni, A.
\& Rikihisa, Y. (2021). An intracellular nanobody targeting T4SS effector inhibits Ehrlichia infection. Proceedings of the National Academy of Sciences, 118(18). DOI: https:// doi.org/10.1073/pnas.2024102118.

Zhu, X., Wang, L., Liu, R., Flutter, B., Li, S., Ding, J., Tao, H., Liu, C., Sun, M. \& Gao, B. (2010). COMBODY: one-domain antibody multimer with improved avidity. Immunology and Cell Biology, 88(6), 667-675. DOI:https://doi.org/10.1038/ icb. 2010.21 